\title{
Cytotoxicity evaluation of chlorhexidine gluconate on human fibroblasts, myoblasts, and osteoblasts
}

\author{
James X. Liu, Jordan Werner, Thorsten Kirsch, Joseph D. Zuckerman, Mandeep S. Virk ${ }^{凶}$ \\ NYU Langone Medical Center, Hospital for Joint Diseases, 301 E. 17th St., New York, NY 10003 \\ $\triangle$ Corresponding author: Mandeep S. Virk, MD, Assistant Professor, Shoulder and Elbow Surgery, Department of Orthopaedic Surgery, NYU Langone \\ Orthopedics, 246 E 20th Street, New York, NY 10003. Office: (646)-356-9408; Fax: 646-356-9413; Mandeep.Virk@nyumc.org \\ (C) Ivyspring International Publisher. This is an open access article distributed under the terms of the Creative Commons Attribution (CC BY-NC) license \\ (https://creativecommons.org/licenses/by-nc/4.0/). See http://ivyspring.com/terms for full terms and conditions.
}

Received: 2018.03.28; Accepted: 2018.07.25; Published: 2018.08.10

\begin{abstract}
Introduction: Chlorhexidine gluconate $(\mathrm{CHX})$ is widely used as a preoperative surgical skin-preparation solution and intra-wound irrigation agent, with excellent efficacy against wide variety of bacteria. The cytotoxic effect of $\mathrm{CHX}$ on local proliferating cells following orthopaedic procedures is largely undescribed. Our aim was to investigate the in vitro effects of $\mathrm{CHX}$ on primary fibroblasts, myoblasts, and osteoblasts.

Methods: Cells were exposed to $\mathrm{CHX}$ dilutions (0\%, $0.002 \%, 0.02 \%, 0.2 \%$, and $2 \%$ ) for either a 1,2 , or 3-minute duration. Cell survival was measured using a cytotoxicity assay (Cell Counting Kit-8). Cell migration was measured using a scratch assay: a "scratch" was made in a cell monolayer following CHX exposure, and time to closure of the scratch was measured.

Results: All cells exposed to $\mathrm{CHX}$ dilutions of $\geq 0.02 \%$ for any exposure duration had cell survival rates of less than $6 \%$ relative to untreated controls $(\mathrm{p}<0.001)$. Cells exposed to $\mathrm{CHX}$ dilution of $0.002 \%$ all had significantly lower survival rates relative to control $(p<0.01)$ with the exception of 1 -minute exposure to fibroblasts, which showed $96.4 \%$ cell survival $(p=0.78)$. Scratch defect closure was seen in $<24$ hours in all control conditions. However, cells exposed to $\mathrm{CHX}$ dilutions $\geq 0.02 \%$ had scratch defects that remained open indefinitely.

Conclusions: The clinically used concentration of $\mathrm{CHX}(2 \%)$ permanently halts cell migration and significantly reduces survival of in vitro fibroblasts, myoblasts, and osteoblasts. Further in vivo studies are required to examine and optimize $\mathrm{CHX}$ safety and efficacy when applied near open incisions or intra-wound application.
\end{abstract}

Key words: chlorhexidine, cytotoxicity, osteoblasts, myoblasts, fibroblasts

\section{Introduction}

Surgical site infections (SSIs) pose major challenges for orthopaedic surgeons. SSIs have led to prolonged hospital stays, increased readmission rates, and adds significant burden to the cost of healthcare. Patients who have experienced SSIs have substantially greater physical limitations and reduction in their health-related quality of life ${ }^{6-10}$. In response to these concerns, multiple antiseptic agents have been used to prevent perioperative bacterial contamination of the wound ${ }^{1-3}$.

Chlorhexidine gluconate ( $\mathrm{CHX})$ is a widely used antiseptic agent and is present in a variety of preparations to prevent infection, including preoperative skin cleansing, surgical site preparation, intraoperative irrigation, CHX impregnated postoperative dressings, and hand antisepsis ${ }^{4}$. Strategies that have recently gained interest involves topically painting wound edges with $2 \%$ chlorhexidine gluconate during primary or revision shoulder replacement surgery, CHX application to the wound prior to postoperative dressing application, and intraoperative dilute $\mathrm{CHX}$ wound irrigation to minimize infection rates. Used as a surface disinfectant for its excellent efficacy against a wide variety of bacteria, CHX is applied to the skin and allowed to dry for 3 minutes as per standard protocol. When used as directed, the minimal bactericidal concentration of $\mathrm{CHX}$ was found to be $0.078 \% \%^{5}$. ChloraPrep [(Becton, Dickinson and Company, Franklin Lakes, NJ) 2\% CHX and 70\% isopropyl 
alcohol] has demonstrated higher effectiveness when used as a preoperative surgical site preparation compared to products that did not contain $\mathrm{CHX}^{6}$. The practice of intra-wound $\mathrm{CHX}$ irrigation has been increasing, particularly in arthroplasty procedures, with its clinical use mirroring that of dilute betadine lavage following total joint arthroplasty ${ }^{5}$. Popular agents such as Irrisept $(0.05 \%$ Chlorhexidine gluconate in sterile water, Irrimax Corporation, Innovation Technologies, Inc., Lawrenceville, GA), which is FDA-approved as an intra-wound irrigation delivery system ${ }^{7}$, are currently being used as a lavage following component implantation and prior to wound closure.

However, there is a paucity of orthopaedic literature regarding the safety of $\mathrm{CHX}$ as an intra-wound irrigation agent and peri-incisional topical antiseptic. Prior studies have demonstrated cytotoxicity to native proliferating cells that are demonstrable in both clinical and cell-based studies $4,8-11$, while other studies support its clinical safety $^{7,12}$. Prior studies have shown CHX solutions to be cytotoxic to human fibroblasts, osteoblasts, and lymphocytes in a time and dose dependent manner $4,8,13,14$, which may possibly delay wound healing or lead to increased rates of wound dehiscence ${ }^{15-20}$. Multiple in vitro studies with $\mathrm{CHX}$ has demonstrated its cytotoxicity to fibroblast cells ${ }^{18,20,21}$. While fibroblasts are a critical cell type in wound healing, myoblasts, and osteoblasts are crucial for skeletal muscle repair and bone healing, respectively ${ }^{22-24}$.

The purpose of this study was to investigate the effect of CHX on not only primary fibroblasts, but also myoblast and osteoblast cell viability and migration using in vitro cell culture techniques. Our primary hypothesis is that the clinically used concentration of CHX diminishes 1) cellular viability and 2) cell migration of fibroblasts, myoblasts, and osteoblasts, as measured by the percent survival of cells via the Cell Counting Kit-8 cell survival assay and the validated scratch test ${ }^{25}$, respectively.

\section{Materials and Methods}

This is a controlled in vitro laboratory study which was performed using three primary human cell types: fibroblasts, myoblasts, and osteoblasts. The effect of different $\mathrm{CHX}$ concentrations at either 1, 2, or 3-minute exposure durations on cell migration, measured via the scratch test, and cell survival, measured using Cell Counting Kit-8 (Dojindo Molecular Technologies, Inc. Rockville, MD), was systematically tested. The short exposure durations were selected to reflect the range of durations of $\mathrm{CHX}$ exposure that are clinically utilized for its antiseptic application. All experiments were performed in triplicate.

\section{Cell Culture}

Primary human fibroblasts (Lonza, Walkersville, MD, CC-2511) were cultured in Fibroblast Basal Medium (Lonza CC-3131) supplemented with human fibroblast growth factor-basic, insulin, gentamicin/ amphotericin-B, and 10\% fetal bovine serum (Lonza CC-4134). Primary human myoblasts (DV Biologics, Yorba Linda, CA, AM002-F) were cultured in Muscle Cellutions Medium (DV Biologics M-GRO-001-500) supplemented with basal media supplement (DV Biologics M-GRO-0010-S) and $20 \mathrm{ng} / \mathrm{ml}$ of human fibroblast growth factor-basic (R\&D systems, Minneapolis, MN, 233-FB-025). Primary human osteoblasts (Lonza CCC-2538) were cultured in Osteoblast Basal Medium (Lonza CC-3208) supplemented with $10 \%$ fetal bovine serum, ascorbic acid, and gentamicin/amphotericin-B (Lonza CC-4193).

Cells were initially seeded in standard sterile $75-\mathrm{cm}^{2}$ tissue culture flasks (Corning Life Sciences, Tewksbury, Massachusetts) at a density of 10,000 cells $/ \mathrm{cm}^{2}$ and grown to $80 \%$ confluency at $37^{\circ} \mathrm{C}$ and $5 \% \mathrm{CO}^{2}$. Cells were passaged in tissue culture flasks until passage 3 , at which time the cells were seeded into 24-well plates (Corning Life Sciences, Corning, NY) at a density of 10,000 cells $/ \mathrm{cm}^{2}$ and cultured until $80-90 \%$ confluent. CHX solutions were made by diluting $4 \%$ chlorhexidine gluconate (Xttrium Laboratories, Mount Prospect, IL) in sterile phosphate buffered saline (PBS, Gibco, Waltham, MA).

\section{Cell Survival Assay}

At $80 \%$ confluency, cells were washed with PBS, then exposed to either $0 \%$ (control), $0.002 \%, 0.02 \%$, $0.2 \%$, or $2 \%$ CHX for 1,2 , or 3 minutes, followed by $3 \mathrm{X}$ wash in PBS and reapplication of cell growth media. The concentrations of $\mathrm{CHX}$ were selected by using the concentration found in the most common surface preparation agent (ChloraPrep 2\% Chorhexidine gluconate), and serially lowering the concentration 3 -fold on a logarithmic scale. Cells were returned to the tissue culture incubator at $37^{\circ} \mathrm{C}$ and incubated for 48 hours. After incubation, cells were washed again with PBS, and 10\% Cell Counting Kit-8 (CCK) solution in cellular growth medium was applied to the cells. The CCK solution contains a highly soluble tetrazolium salt, which receives two electrons from viable cells, to generate an orange formazan dye, allowing colorimetric detection of cellular activity ${ }^{26}$. The cells were then incubated in the tissue culture incubator for 2 hours with the CCK solution, after which absorbance of cellular supernatants were 
measured at $450 \mathrm{~nm}$ according to the manufacturer's protocol. Absorbances of the experimental conditions were compared relative to control absorbance to calculate percent cell survival ${ }^{26}$.

\section{Scratch Test}

At $80 \%$ confluency, the cell monolayer was manually scraped in a straight line in the center of the well to create a "scratch" with a p200 pipette tip. The debris was removed by washing the cells with $1 \mathrm{ml}$ of sterile PBS. After the scratch defect was made, cells were exposed to either $0 \%$ (control), $0.002 \%, 0.02 \%$, $0.2 \%$, or $2 \%$ CHX for 1,2 , or 3 minutes, followed by $3 \mathrm{X}$ wash in PBS and reapplication of cell growth media.

To obtain the same field during image acquisition, reference points were made by marking the outer bottom of the dish with a fine permanent marker. The wells were placed under a phase-contrast microscope, leaving the reference mark just outside of the camera view. Images were captured of the cells before and immediately after the scratch defect was made, after which the cells were immediately returned to the tissue culture incubator at $37^{\circ} \mathrm{C}$ to avoid environmental changes. Subsequent images of the scratch defects were obtained at frequent intervals during the first 72 hours, then every 24 hours until day 14. Time until scratch defect closure, defined as the moment when the cells at the leading edge of the defect made contact with cells from the opposite side, were recorded for each experimental condition ${ }^{25}$.

\section{Statistical Analysis}

The data was reported as mean \pm standard deviation. All cell survival results were compared relative to their respective controls using one-way analysis of variance (ANOVA). Statistical significance was set at $p<0.05$. All statistics were performed using GraphPad Prism Version 7 (GraphPad Software, La Jolla, CA).

\section{Source Funding}

There was no external source of funding for this project.

\section{Results}

\section{Cell Survival Assay}

The results of the cell survival assay are demonstrated in Figure 1. Fibroblasts (Fig 1A), myoblasts (Fig 1B), and osteoblasts (Fig 1C), exposed to $\mathrm{CHX}$ concentrations greater than or equal to $0.02 \%$ for any duration demonstrated significant reduction of cell survival to less than $6 \%$ relative to control $(\mathrm{p}<$ 0.001). For exposure to $0.002 \% \mathrm{CHX}$, cell survival of myoblasts and osteoblasts was significantly reduced to all exposure times. However, cell survival rate of fibroblasts was significantly reduced following 2 and 3 minutes exposure $(p<0.01)$ but not to 1 minute exposure $(\mathrm{p}=0.78)$ of $0.002 \%$ CHX. Individual cell survival percentages and $p$ values are listed in Table 1.

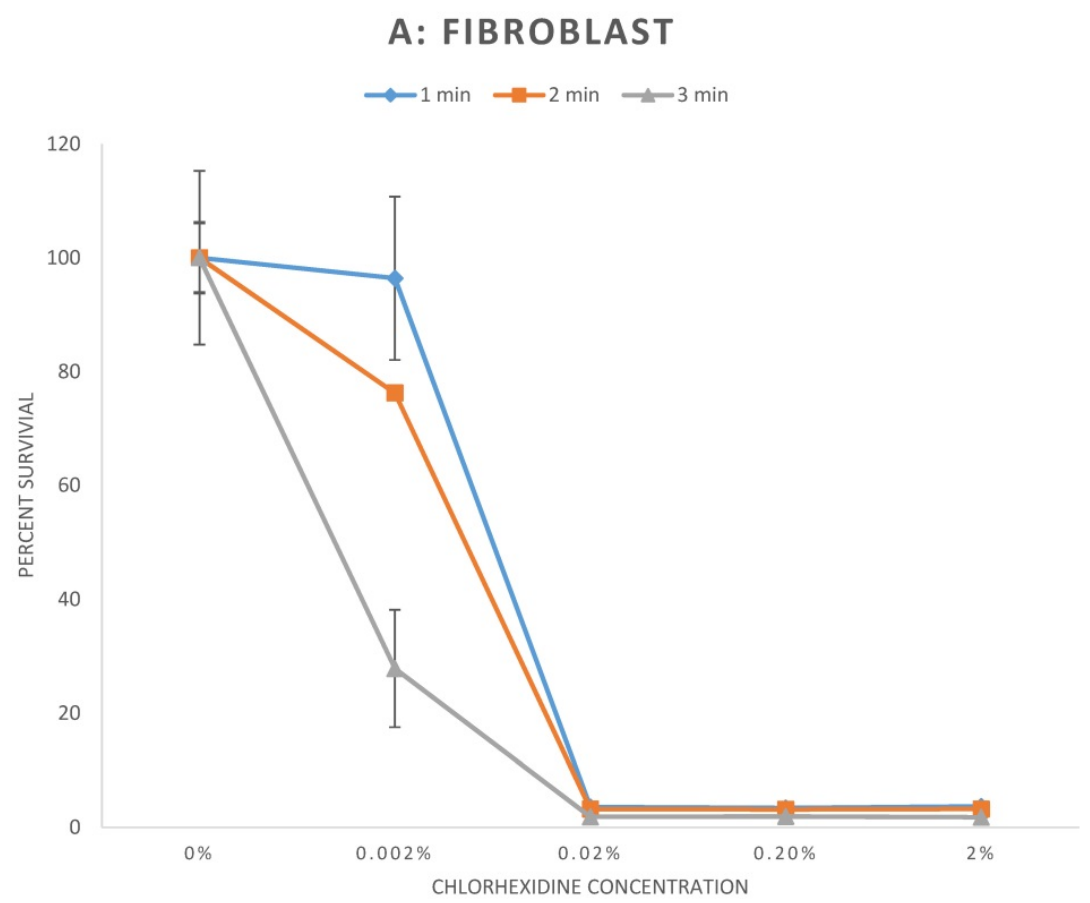



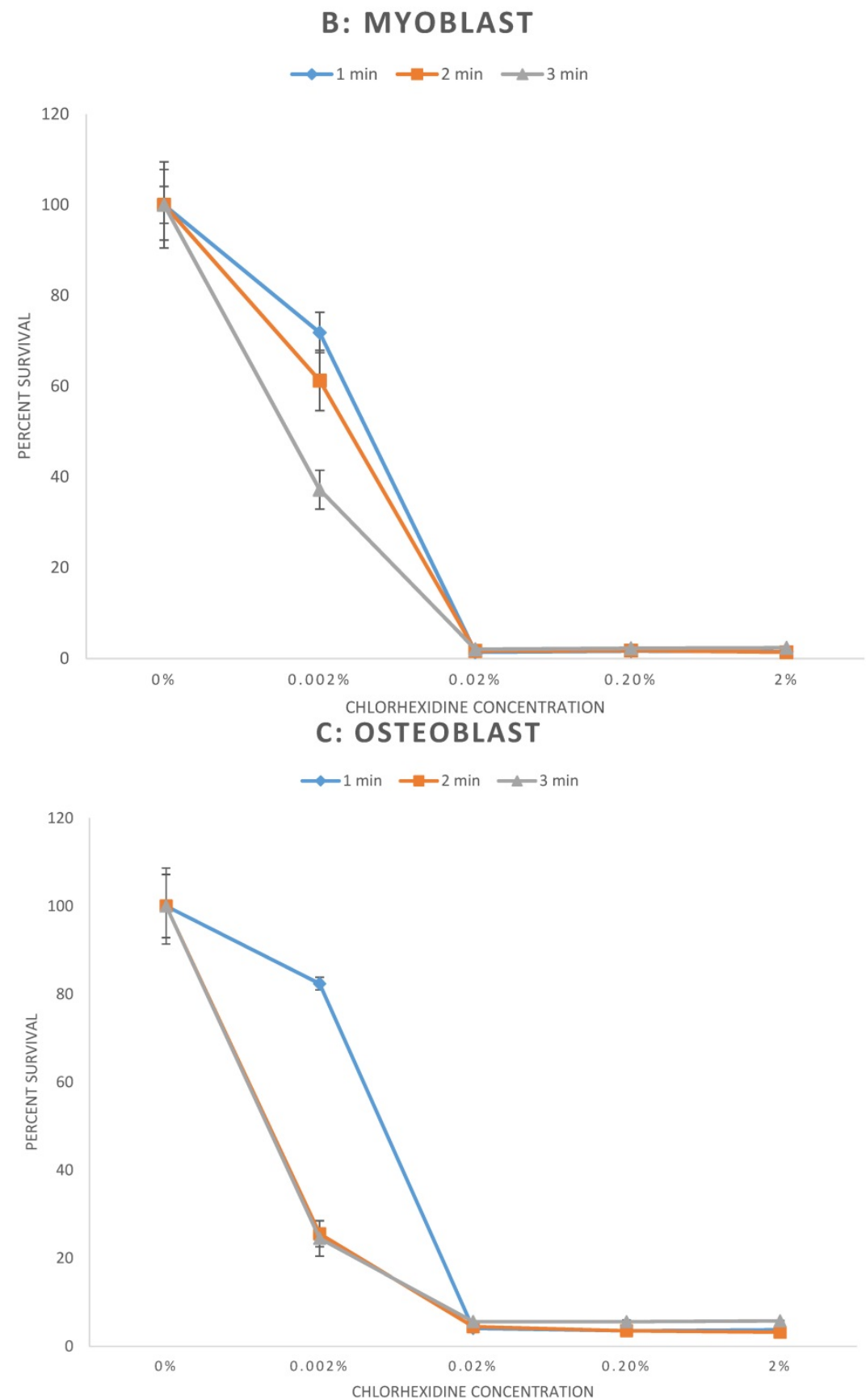

Figure 1. A-C: Percent survival of cells 48 hours after exposure to different concentrations of chlorhexidine gluconate for 1, 2, and 3-minute durations. A) Fibroblast B) Myoblast C) Osteoblast

\section{Scratch test}

The results of the scratch test are demonstrated in Figure 2. After 48 hours of incubation, fibroblasts, myoblasts, and osteoblasts demonstrate closure of the scratch defect under control conditions (exposure to PBS for 3 minutes). In 48 hours, all three cell types could not close their scratch defects after exposure to the clinically used concentration of $2 \% \mathrm{CHX}$ for 3 minutes.

Table 2 summarizes the observations in scratch defect closure at the 24-hour time point for fibroblasts, myoblasts, and osteoblasts after exposure to all CHX concentrations and exposure times. Any exposure to $0.02 \% \mathrm{CHX}$ or greater resulted in open scratch defects (no scratch defect closure) in all cell types. Fibroblasts were able to close their scratch defect after exposure to $0.002 \% \mathrm{CHX}$ for 1 and 2-minute exposure, but not for the 3-minute exposure. Myoblasts were unable to close the scratch defect after exposure to any $\mathrm{CHX}$ concentration for any duration. Osteoblasts were able to close their scratch defects after exposure to $0.002 \%$ CHX for 1-minute, but not for the 2-minute and 3-minute exposures. 
A.

\section{FIBROBLASTS}

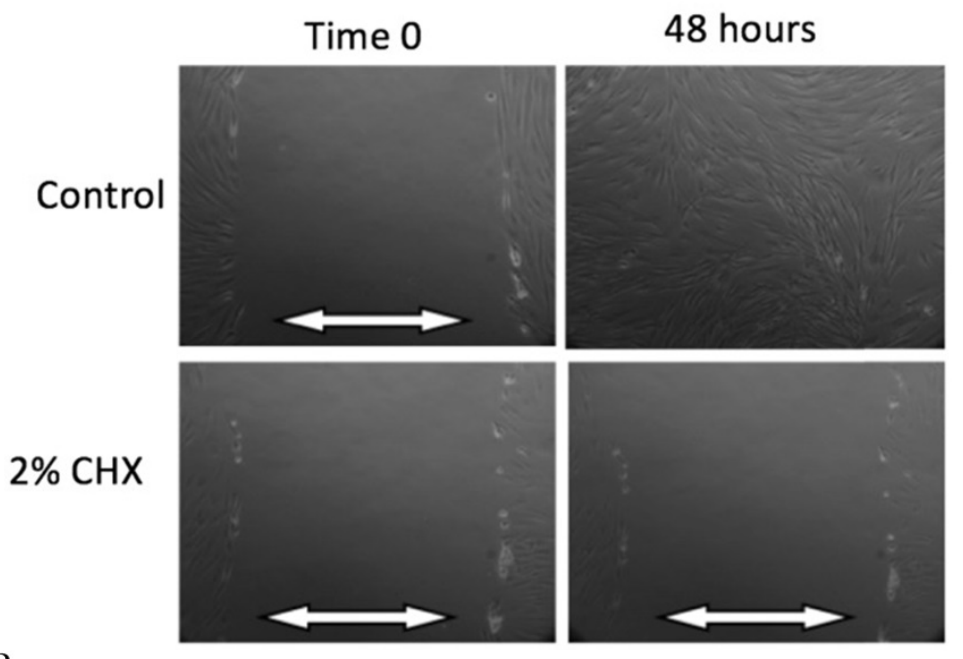

B.

\section{MYOBLASTS}

Time 0

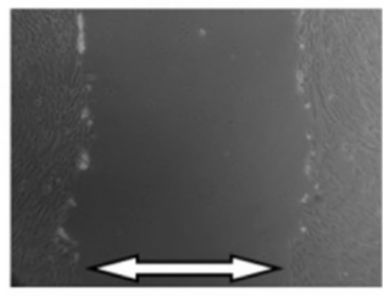

Control

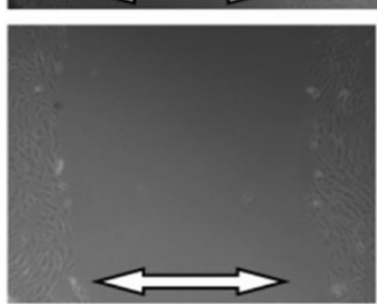

C.

$2 \% \mathrm{CHX}$

\section{OSTEOBLASTS}

Time 0

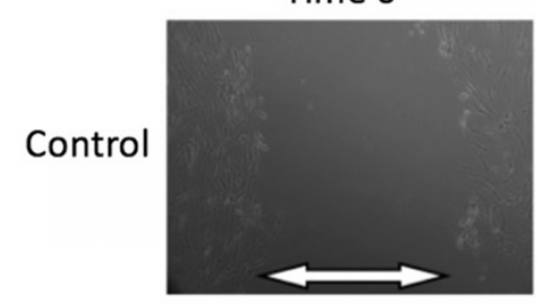

$2 \% \mathrm{CHX}$

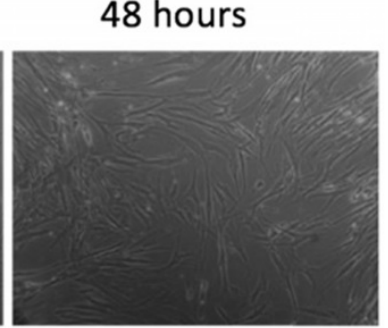

48 hours
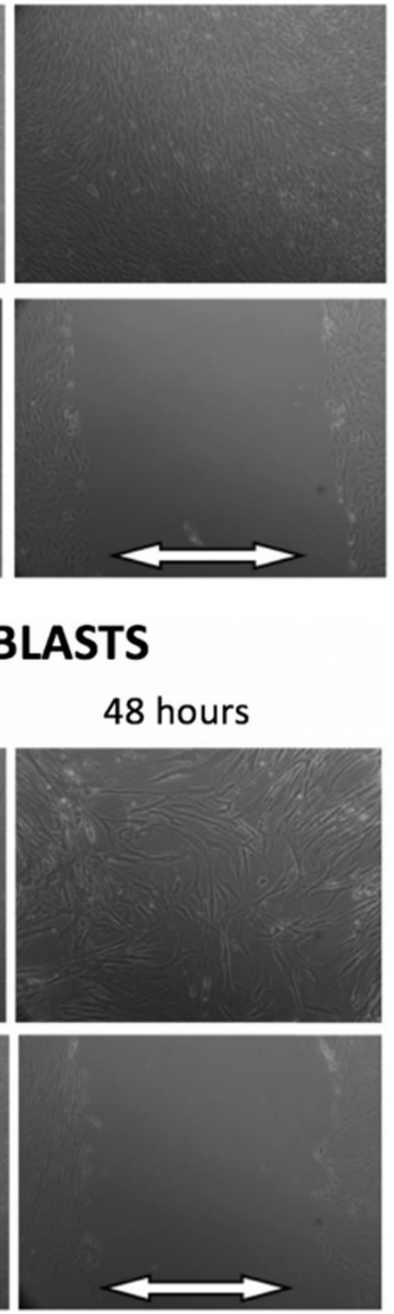

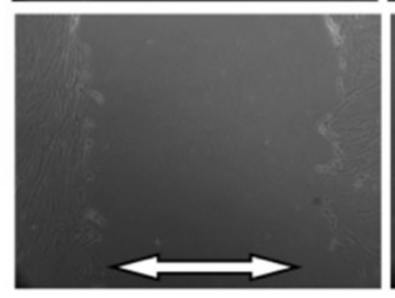

Figure 2. A-C. Scratch test results. At Time 0, scratch defects were initiated in monolayer cell cultures and exposed to either control conditions or the clinically used concentration of $2 \% \mathrm{CHX}$ for 3 minutes. 48 hours later, photos were taken of the scratch defects to observe defect closure. White arrows demonstrate the width of scratch defect. Closure of the scratch defect is seen at 48 hours following exposure to control conditions for all cell types. Open scratch defects are seen at 48 hours following exposure to $2 \% \mathrm{CHX}$ for 3 minutes. A) Fibroblasts, B) Myoblasts, C) Osteoblasts 
Table 1: Percent survival of cells 48 hours after exposure to different concentrations of chlorhexidine gluconate for 1, 2, and 3-minute durations. A) Fibroblast B) Myoblast C) Osteoblast.

\begin{tabular}{|c|c|c|c|}
\hline $\begin{array}{l}\text { Duration of } \\
\text { CHX exposure }\end{array}$ & $\begin{array}{l}\mathrm{CHX} \\
\text { Concentration }\end{array}$ & $\begin{array}{l}\text { Percent cell survival } \pm \\
\text { standard deviation }\end{array}$ & $\begin{array}{l}\text { p-value, experimental } \\
\text { condition vs. control }\end{array}$ \\
\hline \multicolumn{4}{|c|}{ A - Fibroblast } \\
\hline \multirow[t]{5}{*}{1 minute } & Control & $100 \pm 15.3$ & \\
\hline & $0.002 \%$ & $96.4 \pm 14.3$ & 0.78 \\
\hline & $0.02 \%$ & $3.6 \pm 0.2$ & $\mathrm{p}<0.001$ \\
\hline & $0.2 \%$ & $3.4 \pm 0.1$ & $\mathrm{p}<0.001$ \\
\hline & $2 \%$ & $3.7 \pm 0.2$ & $\mathrm{p}<0.001$ \\
\hline \multirow[t]{5}{*}{2 minutes } & Control & $100 \pm 6.3$ & \\
\hline & $0.002 \%$ & $76.3 \pm 0.3$ & 0.003 \\
\hline & $0.02 \%$ & $3.2 \pm 0.1$ & $\mathrm{p}<0.001$ \\
\hline & $0.2 \%$ & $3.2 \pm 0.2$ & $\mathrm{p}<0.001$ \\
\hline & $2 \%$ & $3.2 \pm 0.2$ & $\mathrm{p}<0.001$ \\
\hline \multirow[t]{5}{*}{3 minutes } & Control & $100 \pm 6.0$ & \\
\hline & $0.002 \%$ & $27.9 \pm 10.3$ & $\mathrm{p}<0.001$ \\
\hline & $0.02 \%$ & $1.8 \pm 0.01$ & $p<0.001$ \\
\hline & $0.2 \%$ & $1.9 \pm 0.1$ & $\mathrm{p}<0.001$ \\
\hline & $2 \%$ & $1.8 \pm 0.1$ & $p<0.001$ \\
\hline \multicolumn{4}{|l|}{ B - Myoblast } \\
\hline \multirow[t]{5}{*}{1 minute } & Control & $100 \pm 7.8$ & \\
\hline & $0.002 \%$ & $71.8 \pm 4.5$ & 0.006 \\
\hline & $0.02 \%$ & $1.4 \pm 0.03$ & $\mathrm{p}<0.001$ \\
\hline & $0.2 \%$ & $1.7 \pm 0.1$ & $p<0.001$ \\
\hline & $2 \%$ & $1.5 \pm 0.1$ & $\mathrm{p}<0.001$ \\
\hline \multirow[t]{5}{*}{2 minutes } & Control & $100 \pm 9.5$ & \\
\hline & $0.002 \%$ & $61.3 \pm 6.7$ & 0.004 \\
\hline & $0.02 \%$ & $1.7 \pm 0.1$ & $\mathrm{p}<0.001$ \\
\hline & $0.2 \%$ & $1.8 \pm 0.1$ & $\mathrm{p}<0.001$ \\
\hline & $2 \%$ & $1.4 \pm 0.6$ & $\mathrm{p}<0.001$ \\
\hline \multirow[t]{5}{*}{3 minutes } & Control & $100 \pm 4.1$ & \\
\hline & $0.002 \%$ & $37.2 \pm 4.3$ & $\mathrm{p}<0.001$ \\
\hline & $0.02 \%$ & $2.1 \pm 0.1$ & $\mathrm{p}<0.001$ \\
\hline & $0.2 \%$ & $2.3 \pm 0.1$ & $\mathrm{p}<0.001$ \\
\hline & $2 \%$ & $2.4 \pm 0.1$ & $\mathrm{p}<0.001$ \\
\hline \multicolumn{4}{|l|}{ C - Osteoblast } \\
\hline \multirow[t]{5}{*}{1 minute } & Control & $100 \pm 7.2$ & \\
\hline & $0.002 \%$ & $82.4 \pm 1.4$ & 0.01 \\
\hline & $0.02 \%$ & $4.1 \pm 0.03$ & $p<0.001$ \\
\hline & $0.2 \%$ & $3.5 \pm 0.3$ & $\mathrm{p}<0.001$ \\
\hline & $2 \%$ & $3.8 \pm 0.1$ & $\mathrm{p}<0.001$ \\
\hline \multirow[t]{5}{*}{2 minutes } & Control & $100 \pm 8.6$ & \\
\hline & $0.002 \%$ & $25.5 \pm 2.9$ & $\mathrm{p}<0.001$ \\
\hline & $0.02 \%$ & $4.5 \pm 0.1$ & $\mathrm{p}<0.001$ \\
\hline & $0.2 \%$ & $3.5 \pm 0.1$ & $\mathrm{p}<0.001$ \\
\hline & $2 \%$ & $3.2 \pm 0.1$ & $p<0.001$ \\
\hline \multirow[t]{5}{*}{3 minutes } & Control & $100 \pm 7.2$ & \\
\hline & $0.002 \%$ & $24.5 \pm 4.0$ & $\mathrm{p}<0.001$ \\
\hline & $0.02 \%$ & $5.6 \pm 0.1$ & $p<0.001$ \\
\hline & $0.2 \%$ & $5.6 \pm 0.4$ & $\mathrm{p}<0.001$ \\
\hline & $2 \%$ & $5.8 \pm 0.1$ & $\mathrm{p}<0.001$ \\
\hline
\end{tabular}

Table 2: Scratch test defect closure in fibroblasts, myoblasts, and osteoblasts 24 hours following $\mathrm{CHX}$ exposure for 1, 2, or 3 minute durations. "+" indicates closure. "-“ indicates no closure.

\begin{tabular}{|c|c|c|c|c|c|c|c|c|c|}
\hline & \multicolumn{3}{|c|}{ Fibroblast } & \multicolumn{3}{|c|}{ Myoblast } & \multicolumn{3}{|c|}{ Osteoblast } \\
\hline & $1 \mathrm{~min}$ & $2 \mathrm{~min}$ & $3 \mathrm{~min}$ & $1 \mathrm{~min}$ & $2 \mathrm{~min}$ & $3 \mathrm{~min}$ & $1 \mathrm{~min}$ & $2 \mathrm{~min}$ & $3 \mathrm{~min}$ \\
\hline Control & + & + & + & + & + & + & + & + & + \\
\hline $0.002 \% \mathrm{CHX}$ & + & + & - & - & - & - & + & - & - \\
\hline $0.02 \%$ CHX & - & - & - & - & - & - & - & - & - \\
\hline $0.2 \%$ CHX & - & - & - & - & - & - & - & - & - \\
\hline 2\% CHX & - & - & - & - & - & - & - & - & - \\
\hline
\end{tabular}

\section{Discussion}

The purpose of this study was to determine the effect of various concentrations of $\mathrm{CHX}$ on both cellular viability and cell migration of fibroblast, myoblast, and osteoblast cells in vitro. Cell migration, measured via the scratch assay in this study, is an essential process involved in tissue development, repair, and regeneration. We found that $\mathrm{CHX}$ has a significant cytotoxic effect on cell survival in vitro. These results are comparable to previous investigations that have evaluated the effect of $\mathrm{CHX}$ on fibroblast cells in vitro, ${ }^{87-31}$. Alleyn et al. demonstrated that $0.12 \% \mathrm{CHX}$ exposure for 3 minutes was significantly cytotoxic to ligament fibroblasts relative to control $(\mathrm{p}<0.001)^{28}$. Wilken et al. demonstrated that $0.2 \% \mathrm{CHX}$ exposure to human gingival fibroblasts resulted in immediate cell fixation onto tissue cell culture surfaces relative to control ${ }^{31}$. In this study we extended our investigation to include the myoblasts and osteoblasts in addition to fibroblasts. These three cell types play a significant role in wound healing, muscle repair, fracture healing, bony fusion, and osteointegration of uncemented arthroplasty implants. The clinically used $2 \%$ concentration of CHX significantly reduced cell survival of all cell types, as well as permanently halted cell migration for all cell types, regardless of the exposure duration. The results of this data reinforce the need for further in vivo studies examining the safety and efficacy of CHX in the clinical environment. Furthermore, future in vivo studies are required with biocompatible agents that can be used clinically.

Prior research has demonstrated the toxicity of CHX to human cells. Louis et al. ${ }^{32}$ reported that exposure to $0.2 \% \mathrm{CHX}$ disrupted the cell membrane of poly-morphonuclear leukocytes and caused fixation of their cytoplasmic contents. Goldschmidt et al. ${ }^{30}$ reported that exposing fibroblasts to $0.004 \% \mathrm{CHX}$ for 3-hours inhibited amino acid incorporation and even exposure for 10-minutes was able to prevent protein synthesis 4 -hours later. In a study by Cline et al. ${ }^{29}$, CHX was shown to affect fibroblast proliferation and impair cell adhesion. Chen et $\mathrm{al}^{21}$. exposed human gingival fibroblasts to $2 \% \mathrm{CHX}$ and used the CCK assay to determine cell survival. In their study, cell viability was significantly reduced when exposed to $2 \% \mathrm{CHX}$ for 3 minutes or longer. Similar to findings in this study, Chen et al demonstrated that cell viability was reduced in a time-dependent manner, with cells exposed to $\mathrm{CHX}$ for 10 minutes having cell survival rates significantly lower than the same cells exposed to CHX for only 3 minutes ${ }^{21}$. Flemingson et al. ${ }^{33}$ exposed cultured human fibroblasts to different dilutions of commercially available CHX anti-plaque mouthwash products $(1 \%, 2 \%, 5 \%, 10 \%, 20 \%$, and $100 \%$ ) for 1, 5, and 15 minutes. After exposure, the cells were rinsed twice with Minimum Eagle's 
Medium supplemented with $10 \%$ fetal bovine serum and cell survival was measured after 24-hours. They found that as $\mathrm{CHX}$ concentration increased there was a significant $(\mathrm{p}<0.001)$ difference in fibroblast proliferation - even at their lowest tested concentration $(1 \%)$, exposure to $\mathrm{CHX}$ resulted in in vitro fibroblast survival of $51.7 \%$ compared to no exposure $^{33}$. The dose-dependent cytotoxicity of $\mathrm{CHX}$ on fibroblasts, myoblasts, and osteoblasts is not a unique property of CHX; prior in vitro studies have demonstrated that dilute povidone-iodine and topical vancomycin powder, also used for prevention of surgical site infections, have similarly specific dose-dependent and time-dependent cytotoxicity profiles on fibroblasts, myoblasts, and osteoblasts, as measured via the scratch test and Cell Counting Kit-8 cell survival assay ${ }^{34,35}$.

The bactericidal effect of CHX was not investigated in this study, but has been addressed in many previous studies, 5,15,20. Van Meurs et al. investigated the optimal dilution of various antiseptic solutions that resulted in minimal cytotoxicity against human fibroblasts and mesenchymal stromal cells while retaining a bacterial load reduction of $>99.9 \%$. At 2-minute exposure durations, $\mathrm{CHX}$ was found to have no bactericidal effect at $0.2 \mathrm{~g} / \mathrm{L}$, and maximal bactericidal effect at $10 \mathrm{~g} / \mathrm{L}$, equivalent to $0.02 \% \mathrm{CHX}$ and $1 \% \mathrm{CHX}$, respectively. The minimal bactericidal concentration (MBC) of CHX following 2-minute exposures was found to be $0.078 \%$. Furthermore, they found CHX to have a cytotoxic effect on fibroblasts and mesenchymal cells at concentrations greater than $0.002 \%$, leading to their conclusion that $\mathrm{CHX}$ was fully cytotoxic at concentrations well below the MBC. The study also concluded that, in an in vitro environment, the non-cytotoxic concentrations were less than the MBC for several other commonly used antiseptics, including polyhexanide, octenidine dihydrochloride, and povidone-iodine ${ }^{5}$. Our study corroborates the cytotoxicity profile identified in this study, and also demonstrates similar cytotoxicity of $\mathrm{CHX}$ to osteoblasts and myoblasts cultured in vitro.

In vivo clinical studies demonstrate mixed data regarding the safety and efficacy of $\mathrm{CHX}$. When 1\% CHX was accidentally used for irrigation during knee arthroscopy, the result was cartilage necrosis, non-specific inflammation and synovial fibrosis, persistent pain, swelling, and loss of knee range of motion'. Frisch et al. evaluated the effect of chlorhexidine irrigation on infection rates in 411 total joint arthroplasty patients. They were unable to discern a difference in infection rates or wound healing concerns between chlorhexidine irrigation and using dilute betadine for total hip arthroplasty and $0.9 \%$ saline for total knee arthroplasty 7 .
One of the limitations of this study is that an in vitro cell culture does not truly represent a surgical wound in vivo. Surgical wounds are usually vascularized, comprised of multiple cell types, utilize local and systemic inflammatory responses following tissue injury, and are under various mechanical forces that all affect wound healing. These conditions are not present in a monolayer culture and therefore necessitate in vivo studies to further investigate the effect of CHX. In vivo human progenitor cells are capable of regenerating, whereas in comparison, primary human cells grown in a monolayer tissue culture medium are limited in their regeneration capability. Studies have shown that in vivo human tissue generally has a higher tolerance for antiseptic solutions compared to in vitro tissue culture. It is currently unclear whether the cell death that occurs to the exposed cells of the wound bed will interfere with in vivo wound healing. However, controlled in vitro studies allows for better quantitative analysis on cell types without interference with in vivo factors. Despite these limitations, we have shown that even dilute $\mathrm{CHX}$, at concentrations 100x below the clinically used concentration of $2 \% \mathrm{CHX}$, exert a significant cytotoxic effect on fibroblasts, myoblasts, and osteoblasts in cell cultures. The cytotoxicity of CHX on various cell types warrants further in vivo clinical studies that examine clinical results of direct $\mathrm{CHX}$ application adjacent to or inside open incisional wounds.

\section{Conclusion}

This study has shown that clinically used concentrations of CHX (2.0\%) exerted a cytotoxic effect on osteoblasts, fibroblasts, and myoblasts in vitro. Decreased cell survival and the halting of cell migration were even seen at concentrations as low as $0.002 \%$ across all cell types, demonstrating the profound cytotoxic ability of $\mathrm{CHX}$ at concentrations far below that which is used clinically. While CHX is an effective topical antiseptic agent when used as directed prior to surgery, further clinical in vivo studies are required to characterize the effect on wound and tissue healing when CHX is used near open incisions, on postoperative dressings, or direct intra-wound application. With new agents such as $\mathrm{CHX}$ wound irrigations systems, $\mathrm{CHX}$ impregnated dressings, and the practice of peri-incisional $\mathrm{CHX}$ application becoming more common in clinical practice, it is important to evaluate the clinical effects of CHX application and determine the safest indications for use.

\section{Competing Interests}

The authors have declared that no competing interest exists. 


\section{References}

1. Barker FG, 2nd. Efficacy of prophylactic antibiotic therapy in spinal surgery: a meta-analysis. Neurosurgery. 2002;51(2):391-400; discussion 400-391.

2. Rubinstein E, Findler G, Amit P, Shaked I. Perioperative prophylactic cephazolin in spinal surgery. A double-blind placebo-controlled trial. J Bone Joint Surg Br. 1994;76(1):99-102.

3. Chiang HY, Herwaldt LA, Blevins AE, Cho E, Schweizer ML. Effectiveness of local vancomycin powder to decrease surgical site infections: a meta-analysis. Spine J. 2014;14(3):397-407.

4. George J, Klika AK, Higuera CA. Use of Chlorhexidine Preparations in Total Joint Arthroplasty. J Bone Jt Infect. 2017;2(1):15-22.

5. van Meurs SJ, Gawlitta D, Heemstra KA, Poolman RW, Vogely HC, Kruyt MC. Selection of an optimal antiseptic solution for intraoperative irrigation: an in vitro study. J Bone Joint Surg Am. 2014;96(4):285-291.

6. Saltzman MD, Nuber GW, Gryzlo SM, Marecek GS, Koh JL. Efficacy of surgical preparation solutions in shoulder surgery. J Bone Joint Surg Am. 2009;91(8):1949-1953

7. Frisch NB, Kadri OM, Tenbrunsel T, Abdul-Hak A, Qatu M, Davis JJ. Intraoperative chlorhexidine irrigation to prevent infection in total hip and knee arthroplasty. Arthroplast Today. 2017;3(4):294-297.

8. Mariotti AJ, Rumpf DA. Chlorhexidine-induced changes to human gingival fibroblast collagen and non-collagen protein production. J Periodontol. 1999;70(12):1443-1448.

9. Douw CM, Bulstra SK, Vandenbroucke J, Geesink RG, Vermeulen A. Clinical and pathological changes in the knee after accidental chlorhexidine irrigation during arthroscopy. Case reports and review of the literature. J Bone Joint Surg Br. 1998;80(3):437-440.

10. Tsourounakis I, Palaiologou-Gallis AA, Stoute D, Maney P, Lallier TE. Effect of essential oil and chlorhexidine mouthwashes on gingival fibroblast survival and migration. J Periodontol. 2013;84(8):1211-1220.

11. Hernandez EP, Botero TM, Mantellini MG, McDonald NJ, Nor JE. Effect of ProRoot MTA mixed with chlorhexidine on apoptosis and cell cycle of fibroblasts and macrophages in vitro. Int Endod J. 2005;38(2):137-143.

12. Sukovatykh BS, Pankrusheva TA, Abramova SA. [Optimization of treatment of septic wounds in patients with diabetic foot ulcers]. Vestn Khir Im I I Grek. 2014;173(3):28-32.

13. Giannelli M, Chellini F, Margheri M, Tonelli P, Tani A. Effect of chlorhexidine digluconate on different cell types: a molecular and ultrastructural investigation. Toxicol In Vitro. 2008;22(2):308-317.

14. Almazin SM, Dziak R, Andreana S, Ciancio SG. The effect of doxycycline hyclate, chlorhexidine gluconate, and minocycline hydrochloride on osteoblastic proliferation and differentiation in vitro. J Periodontol. 2009;80(6):999-1005.

15. Hirsch T, Koerber A, Jacobsen F, et al. Evaluation of toxic side effects of clinically used skin antiseptics in vitro. J Surg Res. 2010;164(2):344-350.

16. Hogele AM, Neu J. [Wound closure after irrigation with Octenisept(R) without possibility for drainage]. Unfallchirurg. 2011;114(1):70-72.

17. Hulsemann $W$, Habenicht R. [Severe side effects after Octenisept irrigation of penetrating wounds in children]. Handchir Mikrochir Plast Chir. 2009;41(5):277-282.

18. Muller G, Kramer A. Comparative study of in vitro cytotoxicity of povidone-iodine in solution, in ointment or in a liposomal formulation (Repithel) and selected antiseptics. Dermatology. 2006;212 Suppl 1:91-93.

19. Muller G, Kramer A. Biocompatibility index of antiseptic agents by parallel assessment of antimicrobial activity and cellular cytotoxicity. J Antimicrob Chemother. 2008;61(6):1281-1287.

20. Thomas GW, Rael LT, Bar-Or R, et al. Mechanisms of delayed wound healing by commonly used antiseptics. J Trauma. 2009;66(1):82-90; discussion 90-81.

21. Chen H, Shi Q, Qing Y, Yao YC, Cao YG. Cytotoxicity of modified nonequilibrium plasma with chlorhexidine digluconate on primary cultured human gingival fibroblasts. J Huazhong Univ Sci Technolog Med Sci. 2016;36(1):137-141.

22. Cory G. Scratch-wound assay. Methods Mol Biol. 2011;769:25-30.

23. Goetsch KP, Niesler CU. Optimization of the scratch assay for in vitro skeletal muscle wound healing analysis. Anal Biochem. 2011;411(1):158-160.

24. Man J, Shelton RM, Cooper PR, Landini G, Scheven BA. Low intensity ultrasound stimulates osteoblast migration at different frequencies. I Bone Miner Metab. 2012;30(5):602-607.

25. Liang CC, Park AY, Guan JL. In vitro scratch assay: a convenient and inexpensive method for analysis of cell migration in vitro. Nat Protoc. 2007;2(2):329-333.

26. [Internet] Dojindo Medical Technologies. Cell Counting Kit-8 Cell Proliferation Assay and Cytotoxicity Assay. 2016; https://www.dojindo.com/ TechnicalManual/Manual_CK04.pdf.

27. Flemingson EP, Ambalavanan N, Ramakrishnan T, Vijayalakshmi R. Effect of three commercial mouth rinses on cultured human gingival fibroblast: An in vitro study. Indian Journal of Dental Research. 2008;19(1).

28. Alleyn CD, O'Neal RB, Strong SL, Scheidt MJ, Van Dyke TE, McPherson JC. The effect of chlorhexidine treatment of root surfaces on the attachment of human gingival fibroblasts in vitro. J Periodontol. 1991;62(7):434-438.

29. Cline NV, Layman DL. The effects of chlorhexidine on the attachment and growth of cultured human periodontal cells. J Periodontol. 1992;63(7):598-602.

30. Goldschmidt P, Cogen R, Taubman S. Cytopathologic effects of chlorhexidine on human cells. J Periodontol. 1977;48(4):212-215.
31. Wilken R, Botha SJ, Grobler A, Germishuys PJ. In vitro cytotoxicity of chlorhexidine gluconate, benzydamine- $\mathrm{HCl}$ and povidone iodine mouthrinses on human gingival fibroblasts. SADJ. 2001;56(10):455-460.

32. Louis SM, Pearson RM. A comparison of the effects of nonoxynol-9 and chlorhexidine on sperm motility. Contraception. 1985;32(2):199-205.

33. Flemingson, Emmadi P, Ambalavanan N, Ramakrishnan T, Vijayalakshmi R. Effect of three commercial mouth rinses on cultured human gingival fibroblast: an in vitro study. Indian journal of dental research: official publication of Indian Society for Dental Research. 2008;19(1):29-35.

34. Liu JX, Bravo D, Buza J, et al. Topical vancomycin and its effect on survival and migration of osteoblasts, fibroblasts, and myoblasts: An in vitro study. J Orthop. 2018;15(1):53-58.

35. Liu JX, Werner JA, Buza JIII, Kirsch T, Zuckerman JD, Virk MS. Povidone-iodine Solutions Inhibit Cell Migration and Survival of Osteoblasts, Fibroblasts, and Myoblasts. Spine (Phila Pa 1976). 2017;42(23):1757-1762. 